\title{
Structure and data requirements of an end-use model for residential water demand and return flow
}

\author{
HE Jacobs ${ }^{1 *}$ and J Haarhoff ${ }^{2}$ \\ ${ }^{1}$ GLS, PO Box 814, Stellenbosch 7599, South Africa \\ ${ }^{2}$ Department of Civil and Urban Engineering, Rand Afrikaans University, PO Box 524, Auckland Park 2006, South Africa
}

\begin{abstract}
An end-use model for residential water demand and return flow is presented in this paper. The model requires a unique description of a single residential stand in terms of all its end-uses. The end-uses include toilet flushing, bathing and showering, garden watering, pool water use, leaks, et cetera. Various parameters describe each of the end-uses. The model predicts five components relating to water use and wastewater flow at a residence: indoor water demand, outdoor water demand, hot water demand, wastewater flow volume and concentration of total dissolved solids in the wastewater. The large number of input parameters in an end-use model allow for powerful and detailed analysis of water demand. The various parameters required to populate the model are discussed, guideline values are presented and possible methods for calibration of the model to measured results are proposed. The model calculates 12 monthly results, for each of the five components, to provide a typical seasonal pattern as well as an annual value.
\end{abstract}

Keywords: water consumption - mathematical models, water salinisation, hot water supply

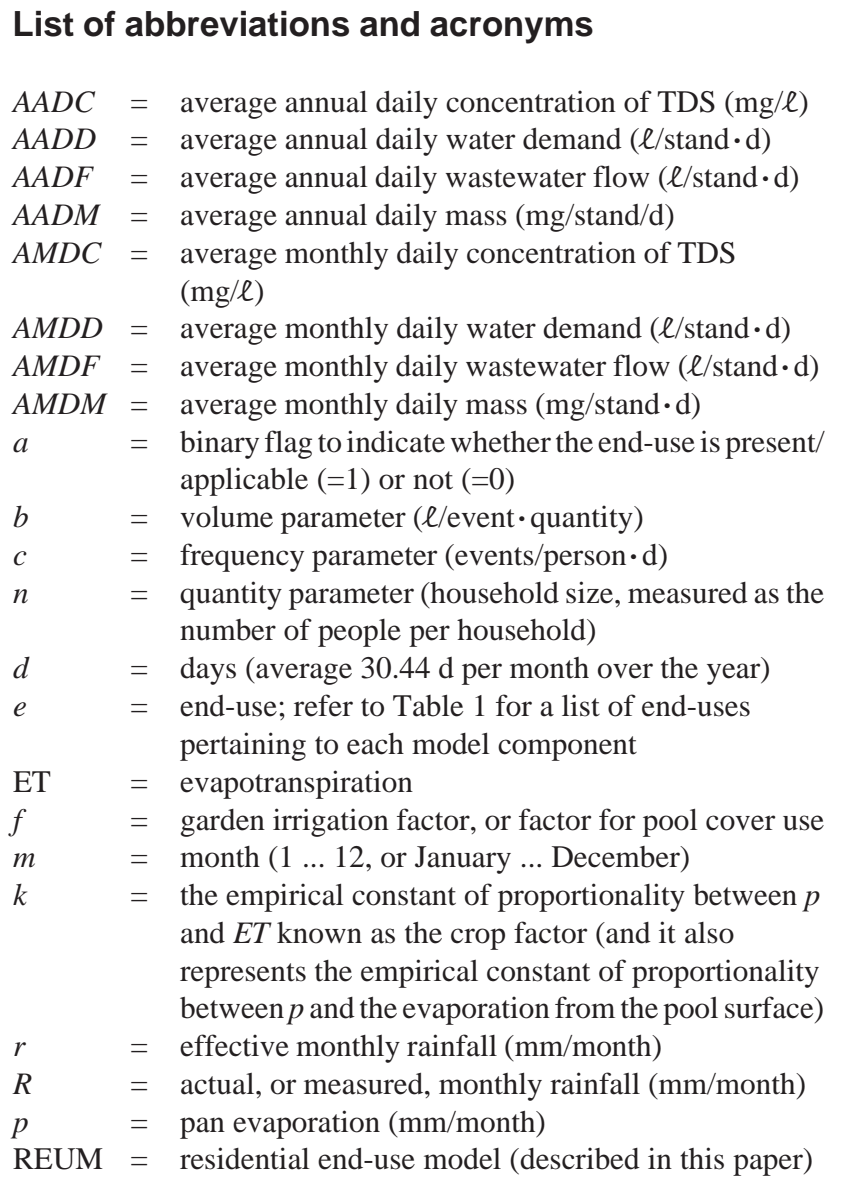

* To whom all correspondence should be addressed.

䍗+2721 880-0388; fax:+2721 880-0389; e-mail: Heinz@GLS.co.za

Received 20 November 2003; accepted in revised form 25 May 2004.

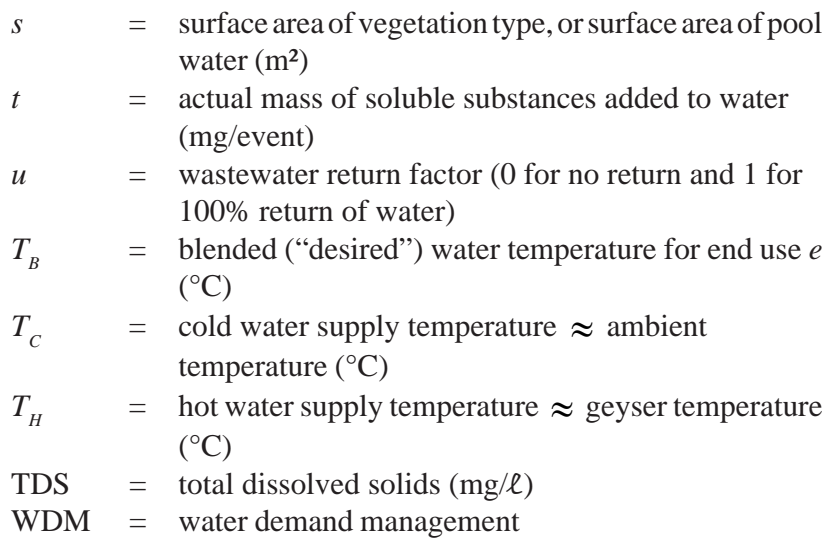

and the subscript:

$c$ denotes cold water

e denotes end-use (refer to Table 1)

$h$ denotes hot water

$i$ denotes indoor

$m$ denotes month (1 ... 12, or January ... December)

$o$ denotes outdoor

$p$ denotes potable water

$s$ denotes soluble substance

$w$ denotes wastewater.

\section{Introduction}

As the national interest of water managers is shifting from traditional emphasis on supply management to water demand management (WDM), there is renewed interest in mathematical models that can predict the effects of new and even hitherto untried WDM measures. One such approach is end-use modelling, which has a rational rather than an empirical basis and which can therefore be used to model scenarios for which no historical data exists. 
This paper describes such an end-use model for residential properties, which predicts not only water demand (split into indoor and outdoor uses), but also hot water demand, wastewater flow and the concentration of total dissolved solids in the wastewater. Application of the model is illustrated in a companion paper (Jacobs and Haarhoff, 2004).

\section{Definitions}

\section{End-use and water demand}

The definition of “end-use" varies from one literature reference to the next depending on the scale of the study area. In this investigation an end-use is considered the smallest identifiable use of water on a stand, such as a toilet flush, shower event, et cetera. A "stand" is defined as a house and surrounding area within the residential property boundary. A flat or similar household can be modelled by setting outdoor parameters in the model equal to zero.

When the term "water demand" is used in this paper without being qualified as "hot", it refers to the total water demand - that is hot and cold water combined.

\section{Soluble substances and total dissolved solids}

In REUM a means had to be developed to compare the potable water supplied to a stand with the wastewater returned from it. The total dissolved solids (TDS) value was considered to be the most appropriate characteristic for this purpose.

Some waste products entering the wastewater at a home are soluble in the water, whilst entrained particles and organic matter are also normally present. The dissolved substances in water, mainly various salts, are of concern because they alter the water chemistry and are not easily removed after being dissolved into the water.

Patterson (1999) discussed many of the sources of the numerous chemicals in domestic wastewater, identified the need to address the issue within the household rather than in subsequent treatment, and provides a detailed explanation for further reading on solutes and salts.

In this paper the term "soluble substance" is used to describe a soluble product before it is dissolved into water, and "total dissolved solids" (TDS) to measure the concentration of soluble substances that have already dissolved in the wastewater stream.

\section{Motivation}

The motivation for the model discussed in this paper is to better understand water demand, hot water demand and wastewater flow on a residential stand. To be more specific, the following issues were deemed of importance:

- With such a model a sensitivity analysis could be conducted on all parameters influencing water use and wastewater flow at a stand in order to determine the most significant parameters these should be the parameters which water managers should focus on.

- The model could be used to evaluate the water saving and subsequent return on investment brought about by individual WDM measures implemented at a stand, such as dual flush toilets, low-flow showerheads, Xeriscaping, et cetera.

- In view of the above water saving, the model could also be used to evaluate the impact of such water saving on the wastewater flow.
- Concentration of TDS in wastewater is considered to increase with decreased water use (assuming that salts added at each end-use in the home remain constant). The model could be used to investigate the TDS in the wastewater. Increased concentration of TDS has a negative impact on the reuse potential of the wastewater and on the environment beyond the wastewater treatment plant.

- The model can estimate the water demand of any single residential stand type in any geographic region. The result can be used to verify existing guidelines for the estimation of water demand and to estimate unaccounted for water.

- The volume of hot water demand for different standards of living was studied by Meyer (2000) who suggested that the availability of a small volume of piped hot water on a stand is a stronger determinant of standard of living than merely an abundance of cold water. The relation of hot water demand to the total water demand, to wastewater flow, and the breakdown by end-use, was not addressed in their work.

- The model could be used to evaluate hot water savings from various WDM measures, which subsequently lead to energy and cost savings. For this reason hot water saving is more valuable from an economic viewpoint than a similar saving of cold water.

- Logic suggests that a more precise relationship exists between hot water demand and wastewater flow than between total water demand and wastewater flow. The model could be used in future work to investigate this relationship, which is important for a few reasons: an increased wastewater temperature may have a negative impact on the environment (Patterson, 1998) and also, hot water demand forms an exclusive and substantial part of the grey-water stream, implying that hot water demand might be a stronger indicator of on-site reuse potential than merely the total water demand.

\section{The residential end-use model}

Studies in South Africa (Garlipp, 1979; Veck and Bill, 2000) include examples of perceived water use by end-use. Significant research on water demand modelling took place in the USA over the years and was arguably initiated by Howe and Linaweaver (1967). This research has culminated in the commercially available IWR-MAIN software suite (PMCL, 1999) that makes use of enduse modelling to conduct WDM, -conservation and -forecasting analyses.

IWR-MAIN is used by a large number of clients worldwide for routine demand management and forecasting. Its applicability to squatter camps in KwaZulu-Natal (Castillo \& Garbharran, 2003) and to a few Rand Water supply areas including Alberton, Boksburg, Centurion and Midrand (Van Zyl et al., 2003), has recently been researched.

DeOreo et al. (1996) were some of the first researchers to specifically address end-uses of demand at a stand, and extended end-use modelling to include hot water (DeOreo et al., 2001). Meyer (2000) also investigated hot water use in South Africa, but the end-uses within a dwelling were not addressed in that work.

Lott et al. (1999) identified the need for knowledge of the salinity of domestic wastewater in view of environmental concerns. The discussion is limited to selected salts added to the wastewater stream for two end-uses, namely washing of clothes and dishes.

The only reference that could be traced where end-use modelling of water demand was combined with wastewater flow and quality estimation is that by Butler (1991), who compiled an enduse model to estimate diurnal wastewater flow patterns from 
residential dwellings. Butler specifically noted that further research in this regard would be valuable. Lauchlan and Dixon (2003) extended Butler's work to model wastewater discharges for houses with conventional and low water use appliances.

A detailed discussion on available water demand models is presented by Van der Merwe (Van der Merwe and Barbour, 2000) and Jacobs (2004). The most significant limitations of the models discussed above include cost, consultant contracts, and complexity of the model regarding structure and/or application. None of the existing models contain the unique aspects of the newly developed REUM.

REUM was developed at the RAU Water Research Group to evaluate the effectiveness and impact of WDM measures. The unique nature of REUM lies in the application of the end-use approach to completely model a residential stand by integrating the following five components:

- Indoor water demand

- Outdoor water demand

- Hot water demand

- Wastewater flow volume

- Concentration of TDS in wastewater

This makes REUM unique and powerful for modelling water demand and wastewater flow. The five components of REUM have been researched individually over the years, but have never been combined. REUM combines all these components into one end-use model.

\section{Mathematical model structure}

\section{Indoor water demand}

In REUM the total water demand of a

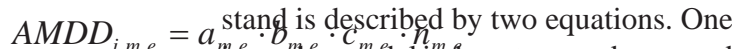
is used,to model imdoor-type end-uses and the other to model outdoor-type end-uses. The former type is characterized by not being dependent upon climatological parameters (e.g. toilet, bath, et cetera), while the latter is (vegetation evapotranspiration and pool evaporation). Pool filtering and miscellaneous outdoor water use are the only two end-uses of water that are physically located outdoors, but are described by the equation for the indoor component.

The average monthly daily demand (AMDD) for an indoor type end-use $e$, and month $m$, is modelled by means of the following equation:

where:

subscript $i$ denotes indoor

$m$ denotes month

$e$ denotes the end-uses as per Table 1

for the indoor component.

Note from the information in the table that the model allows for two unique sets of parameters to describe two toilets - thus a dual flush toilet with a large and small flush volume can be modelled (or of course two normal toilet sizes).

Various desired results can be derived from summing Eq. (1) for all 12 indoor end-uses, and over 12 months. These include the AMDD for all indoor end-uses $\left(A M D D_{i, m}\right.$ in $\ell /$ stand $\left.\cdot \mathrm{d}\right)$, the AADD for any specific indoor end-use $e\left(A A D D_{i, e}\right.$ in $\ell /$ stand $\left.\cdot \mathrm{d}\right)$, and the AADD for all indoor end-uses combined ( $A A D D_{i}$ in $\ell /$ stand $\left.\cdot d\right)$ :

$$
\begin{aligned}
& A M D D_{i, m}=\sum_{e=1}^{12} A M D D_{i, m, e} \\
& A A D D_{i, e}=\sum_{m=1}^{12} A M D D_{i, m, e} / 12 \\
& A A D D_{i}=\sum_{m=1}^{12} \sum_{e=1}^{12} A M D D_{i, m, e} / 12
\end{aligned}
$$

\section{Outdoor water demand}

Outdoor demand comprises garden irrigation for three vegetation types, and pool evaporation (pool filtering and miscellaneous outdoor use are modelled not dependent upon climatological parameters and are better described by the indoor component). Garden irrigation requirements depend on factors influencing vegetation growth. Linaweaver et al. (1963) showed that these factors include rainfall, runoff, infiltration, root zone storage and evaporation. Work by the above authors indicated that garden water irrigation is closely related to moisture deficit, or potential evapotranspiration minus effective rainfall; Johnson (1987) also confirmed this.

A method for calculation of evapotranspiration $(E T)$ is presented by Green (1985) and assumes that over a given period the $E T$ is directly proportional to pan evaporation, $p$. In other words, $E T=(k \cdot P)$, where $k$ is the empirical constant of proportionality known as the crop factor. Evaporation from a pool surface is also

\begin{tabular}{|c|c|c|c|c|c|}
\hline \multicolumn{6}{|c|}{$\begin{array}{c}\text { TABLE } 1 \\
\text { Summary of model components applicable to each end-use }\end{array}$} \\
\hline \multirow[t]{3}{*}{ End-use, $e$} & \multicolumn{5}{|c|}{ Model component } \\
\hline & \multicolumn{3}{|c|}{ Water demand } & \multicolumn{2}{|c|}{ Wastewater } \\
\hline & Indoor & Outdoor & Hot & Volume & TDS \\
\hline Bath & $\mathrm{x}$ & & $\mathrm{x}$ & $\mathrm{x}$ & $\mathrm{x}$ \\
\hline Bathroom basin & $\mathrm{x}$ & & $\mathrm{x}$ & $\mathrm{x}$ & $\mathrm{x}$ \\
\hline Dishwasher & $\mathrm{x}$ & & & $\mathrm{x}$ & $\mathrm{x}$ \\
\hline Kitchen sink & $\mathrm{x}$ & & $\mathrm{x}$ & $\mathrm{x}$ & $\mathrm{x}$ \\
\hline Leaks & $\mathrm{x}$ & & & $\mathrm{x}$ & $\mathrm{x}$ \\
\hline Miscellaneous indoor & $\mathrm{x}$ & & $\mathrm{x}$ & $\mathrm{x}$ & $\mathrm{x}$ \\
\hline Shower & $\mathrm{x}$ & & $\mathrm{x}$ & $\mathrm{x}$ & $\mathrm{x}$ \\
\hline Toilet flush - large (or normal) & $\mathrm{x}$ & & & $\mathrm{x}$ & $\mathrm{x}$ \\
\hline Toilet flush - small (dual flush) & $\mathrm{x}$ & & & $\mathrm{x}$ & $\mathrm{x}$ \\
\hline Washing machine & $\mathrm{x}$ & & $\mathrm{x}$ & $\mathrm{x}$ & $\mathrm{x}$ \\
\hline Miscellaneous outdoor & $\mathrm{x}$ & & & $\mathrm{x}$ & $\mathrm{x}$ \\
\hline Pool filtering & $\mathrm{x}$ & & & $\mathrm{x}$ & $\mathrm{x}$ \\
\hline Pool evaporation & & $\mathrm{x}$ & & & \\
\hline Garden - vegetation type 1 & & $\mathrm{x}$ & & & \\
\hline Garden - vegetation type 2 & & $\mathrm{x}$ & & & \\
\hline Garden - vegetation type 3 & & $\mathrm{x}$ & & & \\
\hline Number of end-uses & 12 & 4 & 6 & 12 & 12 \\
\hline
\end{tabular}
calculated by means of the same equation form, but $k$ would represent the evaporation factor for the pool surface in that case. 
Effective rainfall represents that portion of the rainfall that penetrates the soil and thus has an effect in reducing the water demand of plants. Various methods exist to estimate effective rainfall. In all cases the measured monthly rainfall, $R$ (in $\mathrm{mm} /$ month), is the independent variable. The equation used in REUM to model the effective rainfall, $r$, originates from work by Linsley and Franzini and is reported on by Johnson (1987), who used this method to analyse the garden water demand in Port Elizabeth. The equation states that rainfall less than $25 \mathrm{~mm}$ is $100 \%$ effective and then decreases linearly until a point where rainfall in excess of 152 $\mathrm{mm}$ has an effectiveness of only $89 \mathrm{~mm}$ :

$$
r=\left[\begin{array}{ll}
R & (R<25 \mathrm{~mm}) \\
(0,504) \cdot R+12,4 & (25 \leq R<152) \\
89,0 & (R \geq 152)
\end{array}\right]
$$

In view of the above, the AMDD for an outdoor end-use $e$, and month $m$, is modelled by the following equation:

$$
A M D D_{o, m, e}=\left(f_{m, e} \cdot s_{m, e}\right) \cdot \frac{\left(k_{m, e} \cdot p_{m, e}\right)-r_{m, e}}{d_{m}}
$$

where:

subscript $o$ denotes outdoor

$m$ denotes month

$e$ denotes the end-uses as per Table 1 for the outdoor component.

The AMDD for all outdoor end-uses ( $A M D D_{o, m}$ in $\ell /$ stand $\left.\cdot \mathrm{d}\right)$, the AADD for any specific outdoor end-use $e\left(A A D D_{o, e}\right.$ in $\ell /$ stand $\left.\cdot d\right)$, and the AADD for all outdoor end-uses combined ( $A A D D_{o}$ in $\ell /$ stand $\cdot d$ ) are obtained from summing Eq. (5):

$$
\begin{aligned}
& A M D D_{o, m}=\sum_{e=1}^{4} A M D D_{o, m, e} \\
& A A D D_{o, e}=\sum_{m=1}^{12} A M D D_{o, m, e} / 12 \\
& A A D D_{o}=\sum_{m=1}^{12} \sum_{e=1}^{4} A M D D_{o, m, e} / 12
\end{aligned}
$$

\section{Hot water demand}

The hot water demand can be estimated for each end-use by means of a temperature-volume balance. Two equations can be constructed to solve for the hot and cold water volumes as a function of "known" variables. The three temperature parameters can be estimated and the indoor demand $\left(A M D D_{i, m, e}\right)$ is predicted by the model in the first place and is known. Equation (8) is substituted into Eq.(9) to obtain the desired definition for hot water demand:

$$
\begin{aligned}
& A M D D_{m, e}=A M D D_{c, m, e}+A M D D_{h, m, e} \\
& \left(A M D D_{c, m, e}+A M D D_{h, m, e}\right) \cdot T_{B, m, e}
\end{aligned}
$$

where:

subscript $h$ denotes hot water

$m$ denotes month

$e$ denotes the end-uses as per Table 1 for the hot water component.
The AMDD for all hot water end-uses $\left(A M D D_{h, m}\right.$ in $\ell /$ stand $\left.\cdot d\right)$, the AADD for any specific hot water end-use $e\left(A A D D_{h, e}\right.$ in $\ell /$ stand $\left.\cdot d\right)$, and the AADD for all hot water end-uses combined $\left(A A D D_{h}\right.$ in $\ell /$ stand $\cdot d$ ) are obtained from summing Eq.(10):

$$
\begin{aligned}
& A M D D_{h, m}=\sum_{e=1}^{6} A M D D_{h, m, e} \\
& A A D D_{h, e}=\sum_{m=1}^{12} A M D D_{h, m, e} / 12 \\
& A A D D_{h}=\sum_{m=1}^{12} \sum_{e=1}^{6} A M D D_{h, m, e} / 12
\end{aligned}
$$

In REUM a dishwashing machine is assumed to heat water internally, in other words only cold water is supplied to it. Note also that hot water end-uses are a subset of the indoor end-uses.

\section{Wastewater flow}

The volume of wastewater flow is estimated by means of a dimensionless parameter multiplied with the water demand for each end-use. The return parameter, $u$, is used to describe the fraction of water that is returned to the wastewater system:

$$
A M D F_{w, m, e}=u_{m, e} \cdot A M D D_{m, e}
$$

where:

subscript $w$ denotes wastewater flow volume

$m$ denotes month

$e$ denotes the end-uses as per Table 1 for the wastewater flow component.

The AMDF for all 12 the end-uses $\left(A M D F_{w, m}\right.$ in $\ell /$ stand $\left.\cdot d\right)$, the AADF for any specific end-use $e\left(A A D F_{w e e}\right.$ in $\ell /$ stand $\left.\cdot \mathrm{d}\right)$, and the $\mathrm{AADF}$ for all end-uses combined $\left(A A D F_{w}^{w, e}\right.$ in $\ell /$ stand $\left.\cdot \mathrm{d}\right)$ are obtained from summing Eq.(14):

$$
\begin{aligned}
& A A D F_{w, e}=\sum_{m=1}^{12} A M D F_{w, m, e} / 12 \\
& A A D F_{w}=\sum_{m=1}^{12} \sum_{e=1}^{12} A M D F_{w, m, e} / 12
\end{aligned}
$$

\section{Concentration of TDS in wastewater}

At each end-use the addition of soluble substances to the water stream is possible before the water is returned via the wastewater system. The addition of soluble substances to the wastewater stream by an end-use can be estimated by the following equation:

$$
A M D M_{s, m, e}=t_{m, e} \cdot\left(a_{m, e} \cdot c_{m, e} \cdot n_{m, e}\right)
$$

where:

subscript $s$ denotes soluble substances (added at end-use $e$ ) $m$ denotes month

$e$ denotes the end-uses as per Table 1 for the wastewater TDS component of the model.

The AMDM of soluble substances for all end-uses $\left(A M D M_{s, m}\right.$ in $\mathrm{mg} / \mathrm{stand} / \mathrm{d}$ ), the AADM of soluble substances for any specific enduse $e\left(A A D M_{s, e}\right.$ in $\left.\mathrm{mg} / \mathrm{stand} / \mathrm{d}\right)$, and the AADM of soluble substances for all end-uses combined ( $A A D M_{s}$ in $\left.\mathrm{mg} / \mathrm{stand} / \mathrm{d}\right)$ are obtained from summing Eq.(18):

$$
A M D M_{s, m}=\sum_{e=1}^{12} A M D M_{s, m, e}
$$




$$
\begin{aligned}
& A A D M_{s, e}=\sum_{m=1}^{12} A^{12} M_{s, m, e} / 12 \\
& A A D M_{s}=\sum_{m=1}^{12} \sum_{e=1}^{12} A M D M_{s, m, e} / 12
\end{aligned}
$$

The concentration of TDS in the wastewater stream is dependent upon the mass of soluble substances added to the water and the corresponding volume of wastewater. The AMDC of TDS for all end-uses $\left(A M D C_{w, m}\right.$ in $\mathrm{mg} / \ell$ ), the AADC of TDS for any specific end-use $e\left(A A D C_{w, e}\right.$ in $\left.\mathrm{mg} / \ell\right)$, and the AADC of TDS for all enduses combined $\left(A A D C_{w}\right.$ in $\left.\mathrm{mg} / \ell\right)$ are obtained by dividing the mass of dissolvable solids by the volume of wastewater flow in each case:

$$
\begin{aligned}
& A M D C_{w, m}=A M D M_{s, m} / A M D F_{w, m} \\
& A A D C_{w}=A A D M_{s} / A A D F_{w}
\end{aligned}
$$

The increase in concentration of TDS due to the addition of soluble substances at a residential stand is equal to the difference between the concentration of TDS in the wastewater, $A A D C_{w}$, and in the potable supply water, $A A D C_{p}$.

\section{Simplifying the model}

\section{Number of parameters}

The powerful detailed nature of end-use models is also their main drawback. End-use models are data-hungry and are not easily populated or calibrated. This is also the case with REUM. It is evident that each component of REUM is populated by numerous parameters for each month:

- Indoor water demand - 48 parameters : 4 parameters for each of 12 end-uses (Eq.1)

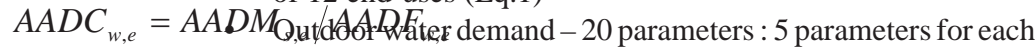
of 4 end-uses (Eq.5)

- Hot water-18 parameters : 3 additional parameters for each of 6 end-uses (Eq.10)

- Wastewater flow volume - 12 parameters : one additional parameter for each of 12 end-uses (Eq. 14)

- Concentration of TDS in wastewater - 13 parameters: one additional parameter for each of 12 end-uses (Eq. 18), plus one parameter for the concentration of salts in the supply water.

It is thus evident that 111 parameters are required to completely model one month. To extend the modelling over a full year, the exercise has to be repeated for each of 12 months, thereby requiring 1332 parameters to fully populate the model. Further analysis of this daunting requirement, however, allows the number of parameters to be drastically reduced by making the following reasonable assumptions:

- The quantity parameter, $n$, is equal to the household size for all end-uses. This results in 11 less parameters per month for the indoor component. Only 37 are now required.

- The monthly pan evaporation, $p$, and rainfall, $R$, are the same for all vegetation types and the pool, thus reducing the required number by 6 parameters. Only 14 parameters instead of 20 are required per month for the outdoor component.

- The hot, cold, and blended water temperature remains the same for all the end-uses. This reduces the number of parameters for the hot water component to 3 .

- Only ten parameters are allowed to vary over 12 months. These are: garden irrigation factors and crop factors for three vegeta- tion types, pan evaporation, rainfall, the factor for pool cover use, and the cold water supply temperature.

- With reference to Eq.(5), there are on average $30.44 \mathrm{~d}$ in a month.

These assumptions reduce the number of parameters required to populate the model significantly without losing any substantial model resolution. Only 79 parameters instead of 111 are required to model all end-uses for any one month, and 189 instead of 1332 to extend the modelling over a full year.

The following number of parameters are now required for each component (over a full year, including all monthly parameters):

- Indoor water demand - 37 parameters.

- Outdoor water demand - 113 parameters.

- Hot water - 14 parameters.

- Wastewater flow volume - 12 parameters.

- Concentration of TDS in wastewater - 13 parameters.

It is possible to populate the model by estimating values for each of these parameters.

\section{Implication of assumptions}

The assumption that only 10 parameters vary over time implies that the following values per end-use remain constant over the modelling period: the presence or absence of fixtures or end-uses at a stand (presence parameter $a$ ); the volume of water per end-use event (volume parameter $b$ ); the frequency of use (frequency parameter $c$ ), household size (quantity parameter $n$ ), the surface area of all vegetation types and the pool, the wastewater return parameter $(u)$, and parameter for the addition of soluble substances $(t)$. Although all results would still be calculated for all 12 months in the model, the same parameter value of these parameters would be applicable for each month in the calculations.

Some parameters remain constant for all end-uses. This implies that the following cannot be adjusted from one end-use to another: monthly rainfall $(R)$, monthly evaporation $(p)$ and cold water temperature $\left(T_{C}\right)$. In other words, if vegetation Type 1 is modelled with a rainfall of $12 \mathrm{~mm} / \mathrm{month}$ for month $m$ the same applies to all other vegetation types and the pool, and if the cold water temperature for month $m$ were $20^{\circ} \mathrm{C}$, this value would be applicable to all end-uses for month $m$.

The evaporation factor (modelled as "crop factor" $k$ ) relating pan evaporation to pool evaporation is assumed to be equal to 1 for all months. The pool evaporation comprises a small fraction of the total water use and does not impact wastewater flow, hot water demand or concentration of TDS in the wastewater, justifying this rather crude assumption.

\section{Simplified model structure}

The equations describing the five model components can be rewritten by integrating these assumptions into Eqs. (1), (5), (10), (14) and (18) for each of the five model components. In each case the average value for all end-uses, for any specific end-use and for all end-uses combined can be obtained by summing these equations as before.

\section{Indoor water demand}

The quantity parameter $(n)$ describes the household size - which is assumed to remain constant over all end-uses and months. Also, all other parameters are assumed to remain constant over all months: 


\section{Outdoor water demand}

The surface area (s) of each vegetation type and the pool are assumed to remain constant over all months, while the pan evaporation $(p)$ and rainfall, thus effective rainfall $(r)$, remain constant over all end-uses. It was also noted that on average there are 30.44 $\mathrm{d}$ in a month:

$$
A M D D_{o, m, e}=\left(f_{m, e} \cdot s_{e}\right) \cdot \frac{\left(k_{m, e} \cdot p_{m}\right)-r_{m}}{30.44}
$$

\section{Hot water demand}

The quantity parameter $(n)$ that describes the household size, the hot water temperature $\left(T_{H}\right)$ and the blended water temperature $\left(T_{B}\right)$ are assumed to remain constant over all end-uses and months. The values for all other parameters, save the cold water temperature $\left(T_{C}\right)$, remain constant over time:

$$
A M D D_{h, m, e}=\frac{\left(T_{B}-T_{H}\right)}{\left(T_{H}-T_{C, m}\right)} \cdot\left(a_{e} \cdot b_{e} \cdot c_{e} \cdot n\right)
$$

\section{Wastewater flow volume}

The same assumptions are valid as for the indoor water demand, but the end-uses ( $e$ ) are those indicated in Table 1 for wastewater flow:

$$
A M D W_{w, m, e}=u_{m, e} \cdot\left(a_{e} \cdot b_{e} \cdot c_{e} \cdot n\right)
$$

\section{Wastewater TDS}

The same assumptions are valid as for the indoor water demand, but the end-uses ( $e$ ) are those indicated in Table 1 for wastewater TDS:

$$
A M D D_{s, m, e}=t_{m, e} \cdot\left(a_{e} \cdot c_{e} \cdot n\right)
$$

\section{Classification of parameters}

\section{Guideline values}

A summary of guideline values for each of the parameters, sorted into five tables for each of the five model components, is presented in Tables 2 to 6. Values typical of suburbs are presented.

The notation of the parameters consists of a character and a subscript identifying the end-use. It was considered sensible to describe the notation of each parameter in two columns, the first presenting the character as per this paper and the second the subscript denoting the appropriate end-use in full text size. A short description of each parameter is included in the fourth column of each Table. The units of measurement, guideline values (low, typical and high values), and the type of parameter are included in the 5th to 9th columns.

\section{Parameter types}

Three types of parameters can be identified:

- Type 1: parameters describing the physical properties of the residential stand (e.g. the household size, toilet flush volume, size of lawn).
- Type 2: parameters describing human habits (e.g. bath-, showerand toilet flush frequency, soluble substances added at an enduse, garden irrigation factor).

- Type 3: climatological and other parameters (e.g. rainfall, evaporation, crop factors, water temperature).

A detailed explanation of each parameter value is provided by Jacobs (2004), but such a discussion is beyond the scope of this paper. However, a brief description of the method of data acquisition according to the three parameter types is provided, and some of the parameters are briefly described in more detail below.

\section{Parameters describing physical properties of the stand (Type 1)}

These parameters are generally the ones that can be determined by a physical survey of any residential stand. Considering the modelling of a single stand at a known location it is relatively easy to determine values for each parameter of this type by means of inspection and measurement of the stand.

When modelling a "typical" stand in a residential area for the purpose of extending the result over a larger number of similar stands, it becomes necessary to estimate values for these parameters. Estimation may also be necessary because a physical inspection is too costly or time consuming, or because not all stands in the area over which the model is to be extended have the same physical properties. In such cases typical values such as presented in Tables 2 to 6 can be used to populate the model.

These values were obtained from two primary sources: literature references to work conducted elsewhere and by means of physical measurement of selected parameter values. The values presented in the Tables are considered to be typical of South African suburbs, although many of the literature references obtained during the review process also originate from the USA, Europe and Australia.

Parameters $a, b$, and $n$ (indoor), s (outdoor), $u$ (wastewater) and $t$ (soluble solids) are of this type. Although the value for $u$ is normally either a 0 or 1 , suggesting respectively that no wastewater is returned or that all the water is returned as wastewater from an end-use, it may be necessary to include a value of between 0 and 1 for pool filtering to indicate that a suburban consumer might sometimes use a manhole close to the pool for pool backwashing.

The average values for each end-use should be used in the model. These averages should be determined based on the required stand(s) to be modelled. If, for example, one stand with four different toilets is to be modelled, the average flush volume of all toilets should be used. On the other hand, if the model is to be extended over a larger number of stands the average toilet flush volume for all toilets (in all homes in the area) should be used.

\section{Parameters describing human habits (Type 2)}

It may be thought that human habits are less easy to determine with accuracy. This would be true for an analyst visiting a stand for a few minutes to determine its properties. It is clear from published figures and recorded information that human habits relating to the end-uses of water are remarkably well defined for typical American, European and high-income South African households, such as those discussed in this paper. Habits of consumers in low-income townships have been less well researched over the years.

A study of the habits relating to the mass of soluble substances added at end-uses is a daunting task. Patterson (1999) found that different products used in Australia (e.g. brand of washing powder) contain significantly different mass of soluble salts, even though 
TABLE 2

Parameters for Component 1 - Mainly indoor water demand

\begin{tabular}{|c|c|c|c|c|c|c|c|c|}
\hline \multirow[t]{2}{*}{ End-Use } & \multicolumn{3}{|c|}{ Parameter } & \multirow{2}{*}{$\begin{array}{c}\text { Unit of } \\
\text { measurement }\end{array}$} & \multicolumn{3}{|c|}{ Values } & \multirow[t]{2}{*}{ Type } \\
\hline & Notation & Footnote & Description & & Low & Typical & High & \\
\hline All & $\mathrm{d}$ & $\begin{array}{l}\text { suburb } \\
\text { (high income) }\end{array}$ & Number of persons & people/stand & 2.6 & 3.3 & 4.7 & 1 \\
\hline All & $\mathrm{d}$ & $\begin{array}{l}\text { township } \\
\text { (low-income) }\end{array}$ & Number of persons & people/stand & 3.8 & 6.2 & 8.2 & 1 \\
\hline
\end{tabular}

\section{End-uses normally located indoors on a stand}

\begin{tabular}{|c|c|c|c|c|c|c|c|c|}
\hline Bath & $\mathrm{a}$ & bath & Presence - binary flag & dimensionless & 0.0 & 1.0 & 1.0 & 1 \\
\hline Bath & $\mathrm{b}$ & bath & Event volume & litres/event & 39.0 & 80.0 & 189.0 & 1 \\
\hline Bath & $\mathrm{C}$ & bath & Frequency of use & events/person/day & 0.22 & 0.24 & 0.90 & 2 \\
\hline Bathroom basin & $\mathrm{a}$ & bathroom basin & Presence - binary flag & dimensionless & 0.0 & 1.0 & 1.0 & 1 \\
\hline Bathroom basin & $\mathrm{b}$ & bathroom basin & Event volume & litres/event & 0.3 & 3.8 & 60.0 & 2 \\
\hline Bathroom basin & $\mathrm{C}$ & bathroom basin & Frequency of use & events/person/day & 3.40 & 3.60 & 3.80 & 2 \\
\hline Dishwasher & $\mathrm{a}$ & dishwasher & Presence - binary flag & dimensionless & 0.0 & 1.0 & 1.0 & 1 \\
\hline Dishwasher & $\mathrm{b}$ & dishwasher & Event volume & litres/event & 15.1 & 25.0 & 43.0 & 1 \\
\hline Dishwasher & $\mathrm{C}$ & dishwasher & Frequency of use & events/person/day & 0.18 & 0.25 & 0.29 & 2 \\
\hline Kitchen sink & $\mathrm{a}$ & Kitchen sink & Presence - binary flag & dimensionless & 0.0 & 1.0 & 1.0 & 1 \\
\hline Kitchen sink & $\mathrm{b}$ & Kitchen sink & Event volume & litres/event & 0.6 & 6.7 & 73.0 & 2 \\
\hline Kitchen sink & $\mathrm{C}$ & Kitchen sink & Frequency of use & events/person/day & 2.00 & 2.00 & 2.10 & 2 \\
\hline Leaks & $\mathrm{a}$ & leaks & Presence - binary flag & dimensionless & 0.0 & 1.0 & 1.0 & 1 \\
\hline Leaks & $\mathrm{b}$ & leaks & Event volume & litres/event & - & 27.4 & - & 1 \\
\hline Leaks & $\mathrm{C}$ & leaks & Frequency of leak & events/person/day & 1.0 & 1.0 & 1.0 & 2 \\
\hline Miscl. indoor & $\mathrm{a}$ & miscl. indoor & Presence - binary flag & dimensionless & 0.0 & 1.0 & 1.0 & 1 \\
\hline Miscl. indoor & $\mathrm{b}$ & miscl. indoor & Event volume & litres/event & - & - & - & 2 \\
\hline Miscl. indoor & $\mathrm{C}$ & miscl. indoor & Frequency of use $(=1)$ & events/day & 1.0 & 1.0 & 1.0 & 1 \\
\hline Shower & $\mathrm{a}$ & shower & Presence - binary flag & dimensionless & 0.0 & 1.0 & 1.0 & 1 \\
\hline Shower & $\mathrm{b}$ & shower & Event volume & litres/event & 7.6 & 59.1 & 303.0 & 1 \\
\hline Shower & $\mathrm{C}$ & shower & Frequency of use & events/person/day & 0.19 & 0.31 & 0.68 & 2 \\
\hline Toilet - normal & $\mathrm{a}$ & toilet large flush & Presence - binary flag & dimensionless & 0.0 & 1.0 & 1.0 & 1 \\
\hline Toilet - normal & $\mathrm{b}$ & toilet large flush & Event volume & litres/event & 8.0 & 14.3 & 26.5 & 1 \\
\hline Toilet - normal & $\mathrm{c}$ & toilet large flush & Frequency of use & events/person/day & 1.7 & 3.7 & 10.3 & 2 \\
\hline Toilet - dual flush & $\mathrm{a}$ & toilet large flush & Presence - binary flag & dimensionless & 0.0 & 0.0 & 1.0 & 1 \\
\hline Toilet - dual flush & $\mathrm{b}$ & toilet large flush & Event volume & litres/event & 4.0 & 6.0 & 6.1 & 1 \\
\hline Toilet - dual flush & $\mathrm{C}$ & toilet large flush & Frequency of use & events/person/day & 0.9 & 1.9 & 5.2 & 2 \\
\hline Toilet - dual flush & $\mathrm{a}$ & toilet small flush & Presence - binary flag & dimensionless & 0.0 & 0.0 & 1.0 & 1 \\
\hline Toilet - dual flush & $\mathrm{b}$ & toilet small flush & Event volume & litres/event & 2.0 & 3.0 & 4.0 & 1 \\
\hline Toilet - dual flush & $\mathrm{C}$ & toilet small flush & Frequency of use & events/person/day & 0.9 & 1.9 & 5.2 & 2 \\
\hline Washing machine & $\mathrm{a}$ & washing machine & Presence - binary flag & dimensionless & 0.0 & 1.0 & 1.0 & 1 \\
\hline Washing machine & $\mathrm{b}$ & washing machine & Event volume & litres/event & 60.0 & 113.6 & 200.0 & 1 \\
\hline Washing machine & C & washing machine & Frequency of use & events/person/day & 0.12 & 0.30 & 0.63 & 2 \\
\hline
\end{tabular}

\section{End-uses normally located outdoors on a stand}

\begin{tabular}{l|l|l|l|l|c|c|c|c|} 
Miscl. outdoor & a & outside tap & Presence - binary flag & dimensionless & 0.0 & 1.0 & 1.0 & 1 \\
Miscl. outdoor & b & outside tap & Event volume & litres/event & 4.4 & 5.0 & 18.9 & 1 \\
Miscl. outdoor & c & outside tap & Frequency of use & events/person/day & 1.00 & 1.00 & 1.00 & 2 \\
Pool filtering & a & pool filtering & Presence - binary flag & dimensionless & 0.0 & 1.0 & 1.0 & 1 \\
Pool filtering & b & pool filtering & Event volume & litres/event & 125.0 & 363.0 & 600.0 & 1 \\
Pool filtering & c & pool filtering & Frequency of use & events/day & 0.012 & 0.024 & 0.036 & 2 \\
\hline
\end{tabular}

Notes:

The large flush of a dual flush toilet and a normal toilet are both modelled by the same parameter(s), thus a dual flush OR normal toilet can be modelled. The flush frequency of a small flush for a dual flush toilet is assumed to be $60 \%$ of the flush frequency of a normal toilet.

Bath and shower frequencies should be evaluated integrally, and combined should equal less than about 1 event/person/day as an annual average value.

the products might have the same application and even the same efficiency. Patterson reported that up to $40 \%$ of some products' mass were merely soluble salts (up to $30 \%$ were found to be sodium salts) used as industrial fillers with no active role during the washing process. During an investigation conducted at RAU as part of this work a similarly wide spread of values for different South African products was found.

It is clear that human habits regarding the addition of soluble substances to the wastewater stream cannot easily be determined unless it is known which brand names' product is used at the stand 
TABLE 3

Parameters for Component 2 - Outdoor water demand

\begin{tabular}{|c|c|c|c|c|c|c|c|c|}
\hline \multirow[t]{2}{*}{ End-Use } & \multicolumn{3}{|c|}{ Parameter } & \multirow{2}{*}{$\begin{array}{l}\text { Unit of } \\
\text { measurement }\end{array}$} & \multicolumn{3}{|c|}{ Values } & \multirow[t]{2}{*}{ Type } \\
\hline & Notation & Footnote & Description & & Low & Typical & High & \\
\hline All, outdoor & $\mathrm{p}$ & Vegetation type 1 & Monthly pan evaporation & $\mathrm{mm} / \mathrm{month}$ & - & Note A & - & 3 \\
\hline All, outdoor & $\mathrm{R}$ & Vegetation type 1 & Monthly rainfall & $\mathrm{mm} / \mathrm{month}$ & - & Note A & - & 3 \\
\hline All, garden irrigation & $\mathrm{f}$ & Vegetation & Garden irrigation factor & dimensionless & 0.0 & 1.0 & 2.0 & 2 \\
\hline Garden irrigation & $\mathrm{s}$ & Vegetation type 1 & Vegetation surface area & m² (refer to Note B) & $15 \%$ & $25 \%$ & $35 \%$ & 1 \\
\hline Garden irrigation & $\mathrm{k}$ & Vegetation type 1 & Monthly crop factor & dimensionless & - & Note A & - & 3 \\
\hline Garden irrigation & $\mathrm{s}$ & Vegetation type 2 & Vegetation surface area & 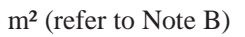 & $5 \%$ & $13 \%$ & $20 \%$ & 1 \\
\hline Garden irrigation & $\mathrm{k}$ & Vegetation type 2 & Monthly crop factor & dimensionless & - & Note A & - & 3 \\
\hline Garden irrigation & $\mathrm{s}$ & Vegetation type 3 & Vegetation surface area & m² (refer to Note C) & - & - & - & 1 \\
\hline Garden irrigation & $\mathrm{k}$ & Vegetation type 3 & Monthly crop factor & dimensionless & - & Note A & - & 3 \\
\hline Pool evaporation & $\mathrm{f}$ & Pool evaporation & Monthly pool cover factor & dimensionless & - & Note A & - & 2 \\
\hline Pool evaporation & $\mathrm{k}$ & Pool evaporation & Evaporation factor & dimensionless & 1.0 & 1.0 & 1.0 & 1 \\
\hline Pool evaporation & $\mathrm{S}$ & Pool evaporation & Pool surface area & $\mathrm{m}^{2}$ & 12.0 & 35.0 & 60.0 & 1 \\
\hline \multicolumn{9}{|c|}{$\begin{array}{l}\text { Notes: } \\
\text { A. Monthly value : Refer to Table } 7 \text { for monthly climatological parameters for a few commercial centres in South African and Namibia } \\
\text { B. The tabulated values are expressed as \% of total stand size for lawn(s) and should be re-calculated for a known stand size to obtain a value in m² } \\
\text { C. If a third vegetation types is modelled and the value is to be estimated, the total of types } 2 \text { and } 3 \text { could equal the value tabulated for type } 2 \text { as a } \\
\quad \text { first approximation. }\end{array}$} \\
\hline
\end{tabular}

\begin{tabular}{|c|c|c|c|c|c|c|c|c|}
\hline \multirow{3}{*}{ End-Use } & \multicolumn{7}{|c|}{$\begin{array}{c}\text { TABLE } 4 \\
\text { Parameters for Component } 3 \text { - Hot water demand }\end{array}$} & \multirow{3}{*}{ Type } \\
\hline & \multicolumn{3}{|r|}{ Parameter } & \multirow{2}{*}{$\begin{array}{l}\text { Unit of } \\
\text { measure- } \\
\text { ment }\end{array}$} & \multicolumn{3}{|c|}{ Values } & \\
\hline & Notation & Footnote & Description & & Low & Typical & High & \\
\hline All, hot water & $\mathrm{T}$ & $\mathrm{C}$ & Monthly average cold water supply temperature & ${ }^{\circ} \mathrm{C}$ & - & Note A & - & 3 \\
\hline All, hot water & $\mathrm{T}$ & $\mathrm{H}$ & Average hot water temperature (geyser) & ${ }^{\circ} \mathrm{C}$ & 60.0 & 65.0 & 70.0 & 1 \\
\hline All, hot water & $\mathrm{T}$ & B & Average blended (desired) water temperature & ${ }^{\circ} \mathrm{C}$ & 34.0 & 40.2 & 42.5 & 2 \\
\hline
\end{tabular}

Notes :

A. Monthly value : Refer to Table 7 for monthly climatological parameters for a few commercial centres in South African and Namibia

\begin{tabular}{|c|c|c|c|c|c|c|c|c|}
\hline \multirow{3}{*}{ End-Use } & \multicolumn{7}{|c|}{$\begin{array}{c}\text { TABLE } 5 \\
\text { Parameters for Component } 4 \text { - Wastewater flow volume }\end{array}$} & \multirow{3}{*}{ Type } \\
\hline & \multicolumn{3}{|c|}{ Parameter } & \multirow{2}{*}{$\begin{array}{l}\text { Unit of } \\
\text { measurement }\end{array}$} & \multicolumn{3}{|c|}{ Values } & \\
\hline & Notation & Footnote & Description & & Low & Typical & High & \\
\hline Bath & $\mathrm{u}$ & bath & Return factor & dimensionless & 0.0 & 1.0 & 1.0 & 1 \\
\hline Bathroom basin & $\mathrm{u}$ & bathroom basin & Return factor & dimensionless & 0.0 & 1.0 & 1.0 & 2 \\
\hline Dishwasher & $\mathrm{u}$ & dishwasher & Return factor & dimensionless & 0.0 & 1.0 & 1.0 & 1 \\
\hline Kitchen sink & $\mathrm{u}$ & kitchen sink & Return factor & dimensionless & 0.0 & 1.0 & 1.0 & 2 \\
\hline Leaks & $\mathrm{u}$ & leaks & Return factor & dimensionless & 0.0 & 0.9 & 1.0 & 1 \\
\hline Miscl. indoor & $\mathrm{u}$ & miscl. indoor & Return factor & dimensionless & 0.0 & 0.9 & 1.0 & 2 \\
\hline Shower & $\mathrm{u}$ & shower & Return factor & dimensionless & 0.0 & 1.0 & 1.0 & 1 \\
\hline Toilet & $\mathrm{u}$ & toilet large flush & Return factor & dimensionless & 0.0 & 1.0 & 1.0 & 1 \\
\hline Toilet & $\mathrm{u}$ & toilet small flush & Return factor & dimensionless & 0.0 & 1.0 & 1.0 & 1 \\
\hline Washing machine & $\mathrm{u}$ & washing machine & Return factor & dimensionless & 0.0 & 1.0 & 1.0 & 1 \\
\hline Miscl. outdoor & $\mathrm{u}$ & miscl. outdoor & Return factor & dimensionless & 0.0 & 0.0 & 1.0 & 2 \\
\hline Pool filter & $\mathrm{u}$ & pool filtering & Return factor & dimensionless & 0.0 & 0.0 & 1.0 & 1 \\
\hline
\end{tabular}


TABLE 6

Parameters for Component 5 - Wastewater flow TDS concentration

\begin{tabular}{|c|c|c|c|c|c|c|c|c|}
\hline \multirow[t]{2}{*}{ End-Use } & \multicolumn{3}{|c|}{ Parameter } & \multirow{2}{*}{$\begin{array}{l}\text { Unit of } \\
\text { measure- } \\
\text { ment }\end{array}$} & \multicolumn{3}{|c|}{ Values } & \multirow[t]{2}{*}{ Type } \\
\hline & Notation & Footnote & Description & & Low & Typical & High & \\
\hline All & AADC & potable water & TDS concentration & mg/litre & 10 & 164 & 215 & 1 \\
\hline Bath & $\mathrm{t}$ & bath & Soluble substance addition & mg/event & 0 & 3900 & - & 2 \\
\hline Bathroom basin & $\mathrm{t}$ & bathroom basin & Soluble substance addition & mg/event & 500 & 3200 & 3900 & 2 \\
\hline Dishwasher & $\mathrm{t}$ & dishwasher & Soluble substance addition & mg/event & 200 & 28800 & 89000 & 2 \\
\hline Kitchen sink & $\mathrm{t}$ & kitchen sink & Soluble substance addition & mg/event & 100 & 2000 & 2500 & 2 \\
\hline Leaks & $\mathrm{t}$ & leaks & Soluble substance addition & mg/event & - & - & - & 2 \\
\hline Miscl. indoor & $\mathrm{t}$ & miscl. indoor & Soluble substance addition & mg/event & - & - & - & 2 \\
\hline Shower & $\mathrm{t}$ & shower & Soluble substance addition & mg/event & 0 & 3900 & - & 2 \\
\hline Toilet & $\mathrm{t}$ & toilet large flush & Soluble substance addition & mg/event & 500 & 1800 & 3000 & 2 \\
\hline Toilet & $\mathrm{t}$ & toilet small flush & Soluble substance addition & mg/event & 9600 & 43700 & 77800 & 2 \\
\hline Washing machine & $\mathrm{t}$ & washing machine & Soluble substance addition & mg/event & 100 & 61000 & 220000 & 2 \\
\hline Miscl. outdoor & $\mathrm{t}$ & miscl. outdoor & Soluble substance addition & mg/event & - & - & - & 2 \\
\hline Pool filter & $\mathrm{t}$ & pool filtering & Soluble substance addition & mg/event & - & 15000 & - & 2 \\
\hline
\end{tabular}

Notes:

The tabulated values for large toilet flush and small toilet flush represent faeces and urine respectively.

It is necessary to add the two values for faeces (large flush) and urine (small flush) together when modelling a normal toilet.

(this normally varies over time depending on the product price, et cetera).

Few values have been reported regarding the mass of soluble substances in faeces and urine, but fortunately those values that have been published for salts in these excrements based on a typical western lifestyle provide some insight into the matter. Research suggests that the daily protein intake influences the salts in - and thus the TDS of wastewater containing - faeces and urine.

The garden irrigation factor, $f$, is a dimensionless value to describe the monthly:

- Efficiency of the irrigation system, i.e. the effectiveness of water reaching the plant root system from the water supply point

- Over- or under- irrigation of vegetation in relation to the ideal water requirement of the vegetation based on moisture deficit calculations.

The value of $f$ is directly related to over-irrigation and indirectly related to the efficiency of the irrigation system - that is the ratio of water reaching the plant roots to that extracted from the supply system for that purpose. Assuming for the moment the presence of a perfectly efficient irrigation system, a value of $f=1$ in any month would represent irrigation equal to the plant's ideal water requirements, $f=0$ would represent the case where no irrigation is practised, and $f=2$ would represent the case where double the ideal volume is irrigated. In mathematical form the garden irrigation factor used in REUM is described by the following equation:

$$
\begin{array}{r}
f=(1 / \text { system efficiency }) \cdot(\text { actual volume irrigated } \\
\text { /ideal water requirement })
\end{array}
$$

Information on the efficiency of irrigation systems and the garden irrigation habits of water consumers is limited, but sufficient information has been published to estimate the system and over- or under-irrigation of garden vegetation by typical consumers. The most helpful information for South Africa is included in work by Veck and Bill (2000) and regular Rand Water consumer surveys (MSSA, 2001).

In the case of the pool, the factor $f$ describes the use of a pool cover. The value could range from 0 (representing no evaporation) to 1 (evaporation equal to pan evaporation) for the case when a pool cover is used in any month or not used respectively.

\section{Climatological and other parameters (Type 3)}

Climatological parameters are probably the parameters in the model that have been the best researched over the years. Recorded values for rainfall and evaporation are available for a large number of weather stations in South Africa. Many stations have monthly values for rainfall, evaporation and temperature covering more than 50 years. The data can be obtained from the South African Weather Service at a minimal cost, or in some instances the information is available free of charge. Publications such as those by Midgley et al. (1994) and Schulze et al. (1997) also include valuable information for estimating values for the climatological parameters required in REUM.

Crop factors and evaporation factors have also been widely researched over the years. Local publications such as those by Green (1985) and Midgley et al. (1994) include values for these parameters. The evapotranspiration of lawn types in relation to pan evaporation has been researched in the USA and also in Australia (Short and Colmer, 1999).

Three parameters pertaining to water temperature are required. Meyer (2000) and measurements during this work established that the hot water supplied from geysers has a temperature of approximately $65^{\circ} \mathrm{C}$ in typical South African suburban homes.

The desired "blended" water temperature appears to be linked to the human body temperature (about $38^{\circ} \mathrm{C}$ ). Relatively small variation around this value has been reported and measured, limited to a tolerance of less than $4^{\circ} \mathrm{C}$ higher or lower than this value. Measurement of desired blended water temperature for a few individuals was conducted during this investigation. The blended 


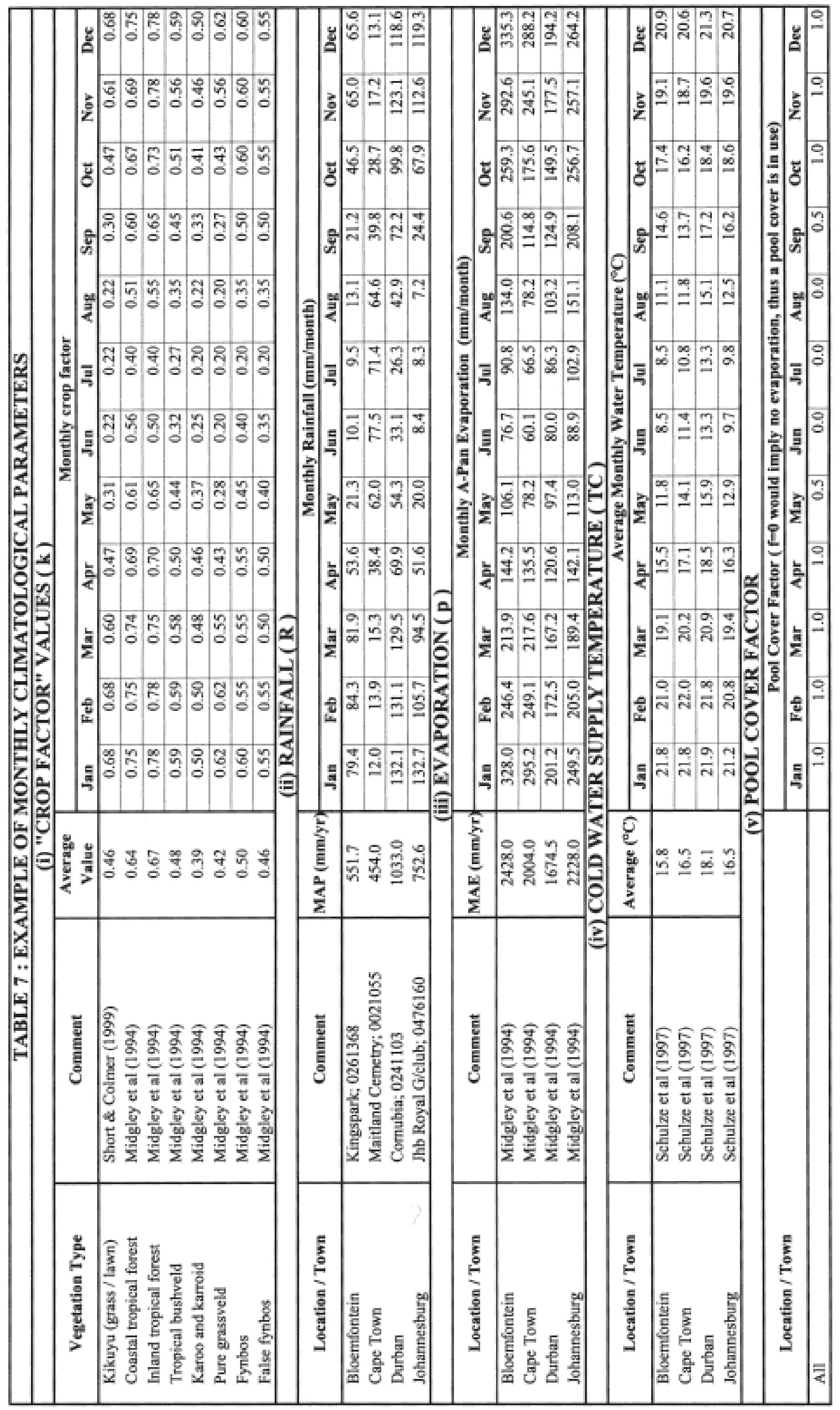


water temperature can be considered to remain relatively constant over different seasons for a specific individual.

Cold water temperature varies in direct proportion to ambient temperature. Cold water supply temperature in a dwelling is a value not often reported or researched, whereas minimum daily, maximum daily, average daily, as well as similar monthly ambient temperature values are often reported. For this reason an assumption was made to relate the monthly cold water and ambient temperature values, based on selected measurements. Average monthly cold water supply temperature is considered to be insignificantly lower than average monthly ambient temperature, implying that the average monthly ambient temperature can be used to estimate the cold water supply temperature in a dwelling.

\section{Discussion}

\section{Miscellaneous water use}

Water use from taps and basins is often grouped together as miscellaneous use in other literature. Various alternatives for modelling such uses were considered. Butler (1991) identified two modes of use for basins (in the bathroom and kitchen): running to waste and emptying. This could be termed time-dependent use and volume-dependent use respectively.

As was found during this investigation, Butler noted that the two modes (running to waste and emptying) result in approximately similar volumes of water use for each event on average, although the volumes cover a wide range.

Following the convention of Butler (1991) a bathroom basin and kitchen sink were included in REUM as unique end-uses. In order to fully describe a stand, miscellaneous indoor use and miscellaneous outdoor use were included to describe water use not residing under one of the other end-uses. Examples of indoor miscellaneous water use may be an uncommon luxury water using appliance or a multi-purpose tap in a low-income dwelling. Typical examples of outdoor miscellaneous uses are car washing and the hosing down of impervious surfaces.

The return flow factor could be adjusted for each of these "miscellaneous" uses to model the appropriate fraction of water returned to the wastewater system in each case.

\section{Bath and shower event description}

In order to investigate a few WDM measures further analysis of parameters describing bath and shower water use could be helpful. Bath event volume and shower event volume are used in REUM as model inputs. However, typical WDM measures could include bathing in less water, shorter shower duration and installation of a low-flow shower nozzle.

Bath water depth multiplied by the bath dimensions, and shower duration multiplied by the shower nozzle flow rate could be used instead to refine the bath and shower event volumes respectively. The former values are often quoted in the literature instead of the bath and shower event volumes. Post-modelling analysis of these variables would enable water managers to investigate the variables for bath water depth, shower nozzle flow rate, and shower duration individually, if required.

\section{Limitations}

\section{Singular modelling of end-uses}

REUM represents one end-use of each type. Whether the model actually includes the correct number of a particular end-use at a stand (correct number of toilets, et cetera) is irrelevant. The frequency parameter is used to model the frequency of use and the model does not require the correct number of a particular end-use to obtain an accurate result. Where more than one appliance for any end-use is present (say two baths) the analyst should understand that the frequency of use should be entered as an average value for the number of times an "end-use" (any of the baths) is used per person per day on the stand, and not how many times a specific appliance (one particular bath) is used.

\section{Experimental model calibration}

This paper deliberately describes the model as if it would be used to obtain five results for a given set of input parameters and not vice versa. It could also become necessary to calibrate all the model input parameters to a given set of measured results for each of the five model components. This concept brings to light a few problems:

- The lack of measured monthly data for a stand over a sufficient time period and for all five of the REUM components (in order to compare these to the REUM results during calibration)

- Corresponding measurement of all the REUM input parameters for the same stand to verify that the calibrated model parameters accurately reflect the measured values

- The complex mathematical procedure of calibrating the model.

The data acquisition and calibration of REUM is a topic for future study. Genetic algorithms (GAs) are considered to be a possible method for calibration in view of the large number of parameters and relatively few equations. GAs have recently been applied successfully to various problems in civil engineering, including the water field (Van Vuuren, 2002; Rouhiainen et al., 2003).

Fortunately all of the input parameters in REUM have sensible meanings and units for which boundary values could be determined by means of logic and knowledge of end-use water demand. The "low" and "high" values presented in Tables 2 to 6 could be used for this purpose. Such boundary values for each parameter would be handy when GAs are used as a mechanism for calibration of the model since it would speed up the calibration process and it would encourage a sensible result.

\section{Conclusion}

REUM is an end-use model for residential water demand and return flow. The model provides a unique description of a single residential stand in terms of all its end-uses. The end-uses included in REUM are the bath, dishwasher, leaks, large toilet flush, small toilet flush (for dual flush toilets), miscellaneous use, washing machine, pool filtering, garden watering for vegetation Type 1, 2 and 3 , and pool evaporation.

The model predicts five components relating to water use and wastewater flow at a residence, namely indoor water demand, outdoor water demand, hot water demand, wastewater flow volume and the concentration of TDS in the wastewater. These monthly results are obtained based on the values of the input parameters. These input parameters can be estimated for any stand type, any set of human habits of the consumer(s) and any geographical area.

The practical application of REUM is not only limited to the estimation of indoor- and outdoor water demand, hot water demand, return flow, and the concentration of TDS in the wastewater, but extends for example to the evaluation of WDM measures and their impact on wastewater flow and-TDS and sensitivity analysis of parameters affecting water use. 
The analyst can easily evaluate different WDM measures, estimate the water saving for any WDM measure, and conduct demand estimation for a certain type of stand with REUM. Water use for different stand types can be estimated based on typical water use habits of consumers and typical stand types - for example stands depicting certain socio-economic profiles, such as suburban and township stands in South Africa. The effect of any such WDM measure on wastewater flow and salinity of wastewater can also be estimated. Note that the model will under-estimate the flow into a wastewater treatment plant as it neglects ingress of stormwater and infiltration of groundwater downstream of the modelled stand.

REUM is a powerful and comprehensive tool for residential water demand and sewer flow end-use analysis, has a relatively simple mathematical structure and could be a useful base for further refinements in this regard.

\section{References}

BUTLER D (1991) A small-scale study of wastewater discharges from domestic appliances. Water Environ. Manage. J. 5 (4) 178-185.

CASTILLO G and GARBHARRAN HP (2003) The IWR-MAIN water model and its applicability for water provision to squatter communities in KwaZulu-Natal. Association of American Geographers, Illustrated paper session: 5508. South Africa into the 21st Century (Sponsored by the Africa Specialty Group).

DeOREO WB, HEANY JP and MAYER PW (1996) Flow trace analysis to assess water use. J. Am. Waste Water Assoc. 1 79-90.

DeOREO WB, DIETEMANN A, SKEEL T, MAYER PW, LEWIS and SMITH J (2001) Retrofit realities. J. Am. Waste Water Assoc. 3 58-72.

GARLIPP DKCO (1979) Water Consumption Patterns in Urban Areas. M.Sc. Thesis, University of Pretoria, Water Research Group, Department of Chemical Engineering.

GREEN GC (1985) Estimated Irrigation Requirements of Crops in South Africa (Part 1). Department of Agriculture and Water Supply, Soil and Irrigation Research Institute.

HOWE CW and LINAWEAVER FP (1967) The impact of price on residential water demand and its relation to system design and price structure. Water Resour. Res. 3 (1)13-32.

JACOBS HE (2004) A Conceptual End-use Model for Residential Water Demand and Return Flow. Ph.D., Rand Afrikaans University, Department of Civil Engineering, April 2004.

JACOBS HE and HAARHOFF J (2004) Application of a residential enduse model for estimating cold- and hot water demand, wastewater flow and -salinity. Water SA 30 (3) 305-316.

JOHNSON EH (1987) Flow Data Acquisition and Forecasting System for a Water Distribution Network. Laureatus in Technology, Department Civil Engineering, Port Elizabeth Technikon.

LAUCHLAN CS AND DIXON A (2003) Modelling of water discharges for houses with conventional and low water use appliances. In:
Maksimovic C, Butler D and Mermon FA (eds.) Advances in Water Supply and Management. Swets and Zeitlinger, Lisse. 517-524.

LINAWEAVER FP, GEYER JC and WOLFF JB (1963) Final Report on Phase 1 of the Residential Water Use Research Project. Department of Environmental Engineering Science, Johns Hopkins University, October 1963.

LOTT S, PATTERSON RA and PETROV R (1999) On-site systems soils, salts and solutes. Proc. On-Site '99 Conference : Making On-site Wastewater Systems Work. 13-15 July 1999. University of New England, Armidale.

MEYER JP (2000) A review of domestic hot-water consumption in South Africa. Res. Dev. J. 16 (3) 55-61.

MIDGLEY DC, PITMAN WV and MIDDLETON B J (1994) Surface Water Resources of South Africa. Report Number 298/5.1/94, compiled for the Water Research Commission by the University of the Witwatersrand.

MSSA (2001) Rand Water Household Survey: Compiled for Rand Water Marketing Department by Marketing Surveys and Statistical Analysis (MSSA).

PATTERSON RA (1998) Household Chemical Impact on Effluent Reuse. Poster presentation to WaterTech Conference Convention Centre, Brisbane, 27-28 April.

PATTERSON RA (1999) Reuse Initiatives Start in the Supermarket. New South Wales Country Convention, Institution of Engineers Australia, 6-8 Aug, Northern Group.

PMCL (1999) IWR-MAIN Water Demand Management Suite: User's Manual and System Description. Planning and Management Consultants, January.

ROUHIAINEN CJ, TADE CO and WEST G (2003) Multi-objective genetic algorithm for optimal scheduling of chlorine dosing in water distribution systems. In: Maksimovic C, Butler D and Mermon FA (eds.) Advances in Water Supply and Management. Swets and Zeitlinger, Lisse. 459-558.

SCHULZE RE, MAHARAJ M, LYNCH SD, HOWE BJ and MELVILTHOMSON B (1997) South African Atlas of Agrohydrology and Climatology. Water Research Commission Report No TT 82/96, ACRU Report 46.

SHORT D and COLMER T (1999) Update on Western-Australia Water Use Study: A Comparison of Eleven Turf Grass Genotypes during Summer in Perth. University of Western Australia, November.

VAN DER MERWE B and BARBOUR E (2000) Literature Study on Water Demand Management and Water Demand Forecasting Models. A report compiled for Rand Water by Environmental Engineering Services, December.

VAN VUUREN SJ (2002) Application of genetic algorithms - Determination of the optimal pipe diameters. Water SA 28 (2) 217-223.

VAN ZYL JE, HAARHOFF J and HUSSELMAN ML (2003) Potential Application of End-Use Demand Modelling in South Africa. J. S. Afr. Inst. Civ. Eng. 45 (2).

VECK GA and BILL MR (2000) Estimation of the Residential Price Elasticity of Demand for Water by Means of a Contingent Evaluation Approach. Water Research Commission Report No 790/1/00. 